\title{
STRATEGI PEMASARAN PRODUK ARRUM BPKB PADA PEGADAIAN SYARIAH CPS MARGONDA
}

\author{
Masitoh Syahidah', Azis Budi Setiawan², Endang Ahmad Yani
}

\author{
${ }^{1}$ Guru SDIT Cahaya Fikri Bontang. Email : Elsyahidah17@gmail.com, \\ ${ }^{2}$ Wakil Ketua I Bidang Akademik Sekolah Tinggi Ekonomi Islam SEBI, Depok, Jawa Barat. \\ Email:setiawan.aziz@gmail.com, \\ ${ }^{3}$ Wakil Ketua IV Sekolah Tinggi Ekonomi Islam SEBI, Depok, Jawa Barat. Email: \\ ahyani2009@gmail.com
}

\begin{abstract}
This research is a quantitative research, which aims to know the marketing strategy that can be done by shariah pawnshops of ARRUM BPKB financing products. The population in this study is all employees associated with ARRUM products. While the sample used in this study is saturated samples. The type of data that the author uses is the primary and secondary data types. The method used to formulate strategies using SWOT Analysis. The results of this study indicate that the product ARRUM BPKB located in Quadrant I is in Progressive conditions. Under these conditions, the $S$-O strategy is the right one to apply. And based on the calculation of QSPM, the priority of strategy with the highest Value of Attractiveness (TAS) is the socialization of cheaper ujroh cost to UMKM in a more massive way.
\end{abstract}

Keywords: Strategy, Marketing, Pawnshop, SWOT, UMKM.

\section{PENDAHULUAN}

Indonesia adalah negara yang sebagian besar penduduknya beragama Islam dan sebagai umat muslim yang taat, sudah seharusnya kita berusaha sebaik mungkin untuk menjalankan perintah-Nya dan menjauhi larangan-Nya. Seperti halnya dalam kehidupan bertransaksi. Kita sebagai umat muslim dilarang untuk bertransaksi dengan cara yang haram dan salah satunya adalah dilarangnya mengambilriba dari sebuah transaksi. Munculnya lembaga keuangan syariah menjadi penolong dan jalan keluar baru bagi masyarakat Indonesia terutama umat muslim yang sebagian besar menjadi penduduk di Indonesia.

Saat ini, selain lembaga keuangan syariah bank, terdapat pula lembaga keuangan syariah non-bank. Adanya lembaga keuangan syariah non-bank ini menjadi kabar baik bagi masyarakat Indonesia terutama umat muslim yang ingin bertransaksi tanpa harus khawatir apakah sudah sesuai syariat atau belum terutama yang kondisi ekonominya adalah menengah kebawah. Karena transaksi di lembaga keuangan syariah non bank lebih mudah dalam pemenuhan permohanan pembiayaan. Sehingga masyarakat dapat memenuhi kebutuhannya akan uang tunai untuk mengembangkan usahanya.

Solusi untuk menjawab keinginan masyarakat terutama masayarakat menengah kebawah dalam memenuhi kebutuhan akan uang tunai untuk memenuhi kebutuhan sehari-hari maupun untuk kebutuhan produktif lainnya 
Jurnal Ekonomi dan Perbankan Syariah

Vol. 7. No.2, Agustus 2018: 64-82, ISSN (cet): 2355-1755 | ISSN (online): 2579-

6437

| 65

dengan proses yang cepat dan prosedur yang mudah adalah melalui pembiayaan gadai syariah(rahn). Pembiayaan melalui gadai syariah ini tersedia di lembaga keuangannon-bank yaitu pegadaian syariah. Pegadaiansyariah merupakan salah satu badan usaha di Indonesia yang secara resmi mempunyai izin untuk melaksanakan kegiatan lembaga keuangan berupa pembiayaan dalam bentuk penyaluran dana ke masyarakat atas dasar hukum gadai(Amin, 2005, p. 12).

\section{Tabel 1 Omzet (Outstanding) Produk Gadai Syariah dan Pembiayaan Mikro Syariah di Cabang Pegadaian Syariah (CPS) Margonda}

\begin{tabular}{|c|c|c|c|}
\hline \multirow[b]{2}{*}{ Produk } & \multicolumn{3}{|c|}{$\begin{array}{l}\text { Tahun } \\
\text { (Dalam Rupiah) }\end{array}$} \\
\hline & 2014 & 2015 & 2016 \\
\hline Ar-Rum & 212.664 .100 & 245.840 .000 & 249.406 .006 \\
\hline Amanah & 927.350 .604 & 927.350 .604 & 1.031 .935 .280 \\
\hline Rahn & 16.217 .100 .000 & 15.815 .210 .000 & 16.887 .000 .000 \\
\hline
\end{tabular}

Sumber :Laporan Porotfolio Cabang Pegadaian Syariah (CPS) Margonda 2015-2016

Data di atas adalah data pertumbuhan omzet dan nasabah produk ARRUM dan dua produk pembiayaan lainnya di Pegadaian Syariah CPS Margonda. Dari data diatas dapat kita lihat bahwa jumlah nasabah gadai syariah (Rahn) dari tahun ke tahun selalu lebih unggul dibanding dua produk pembiayaan lainnya (Amanah dan ARRUM) begitu juga dengan omzet yang diperoleh, berbanding lurus dengan peningkatan jumlah nasabah dan produk gadai syariah tetap selalu yang paling unggul. Kecuali pada tahun 2014, jumlah nasabah terlihat mengalami penurunan yang signifikan, ini dikarenakan Pegadaian telah menerapkan sistem online di seluruh Indonesia sehingga data nasabah yang sebelumnya dihitung dari jumlah akun (account number), saat ini menggunakan sistem single account. Hal ini berakibat pada perubahan data jumlah nasabah.

Inilah yang menjadi perhatian penulis mengapa produk ARRUM pertumbuhannya sangat kecil jika dibandingkan dengan produk Rahn. Padahal jika dilihat peluang untuk ARRUM ini sangat besar, berhubung banyaknya jumlah UMKM yang ada di Kota Depok. Mungkin salah satu penyebab masih sedikitnya jumlah nasabah produk ARRUM ini karena banyak masyarakat yang belum tau akan produk ini.

\section{LANDASAN TEORI}

\subsection{Strategi Pemasaran}


Strategi pemasaran adalah logika pemasaran yang dilaksanakan dengan harapan bahwa unit bisnis akan mencapai sasaran pemasaran. Strategi pemasaran terdiri dari strategi spesifik unuk pasar sasaran, penentuan posisi produk, bauran pemasaran, dan tingkat pengeluaran pemasaran (Kotler \& Amstrong, 2003, p. 54). Proses strategi pemasaran Islami berbeda dengan strategi pemasaran konvensional, namun mempunyai tujuan yang sama yaitu untuk meningkatkan jumlah nasabah.

\subsection{Proses Manajemen Strategi}

Proses manajemen strategi terdiri atas perumusan strategi, penerapan strategi, dan penilaian strategi. Perumusan strategi mencakup pengembangan visi dan misi, identifikasi peluang dan ancaman eksternal suatu organisasi, kesadaran akan kekuatan dan kelemahan internal, pencarian strategi-strategi alternatif, serta pemilihan strategi tertentu untuk mencapai tujuan. Proses manajemen strategi merupakan suatu proses yang terikat, proses manajemen startegis menurut (David, 2012)) terdiri dari tiga tahap:

\section{a. Tahap Formulasi Strategis}

Tahap ini terdiri dari analisis lingkungan internal dan eksternal perusahaan, mengidentifikasi peluang dan ancaman eksternal perusahaan, menentukan kekuatan dan kelemahan internal, menetapkan tujuan jangka panjang,merumuskan strategi alternatif tertentu yang akan dilaksanakan. Setelah melakukan analisis lingkungan dan menetukan kemana organisasi akan diarahkan berdasarkan strategic architecture.

\section{b. Tahap Implementasi Strategi}

Setelah sebuah strategi diformulasikan, strategi tersebut harus dikembangkan secara logis dalam bentuk tindakan. Tahap inilah yang disebut dengan implementasi strategi. Masalah implementasi ini cukup rumit, oleh karena itu agar penerapan strategi organsasi dapat berhasil dengan baik, manajer harus memiliki gagasan yang jelas tentang isu-isu yang berbeda dan bagaimana cara mengatasinya.

\section{c. Tahap Evaluasi dan Pengendalian Strategi}

Evaluasi dan pengendalian adalah proses dari aktivitas-aktivitas perusahaan dan hasil kinerja dimonitor dan kinerja sesungguhnya dibandingkan dengan kinerja yang diinginkan. Para manajer disemua level menggunakan informasi hasil kinerja untuk melakukan tindakan perbaikan dan memecahkan masalah. Walaupun evaluasi dan pengendalian merupakan elemen akhir yang utama dari manajemen strategis, elemen itu juga dapat menunjukan secara tepat kelemahan-kelemahan dalam implementasi strategi.

\subsection{Formulasi Strategi}

\section{a. Analisis Lingkungan Eksternal}

Faktor eksternal ini mempengaruhi terbentuknya opportunities and threat (O dan T). Dimana faktor ini menyangkut dengan kondisi-kondisi yang terjadi di luar perusahaan yang mempengaruhi dalam pembuatan keputusan 
Jurnal Ekonomi dan Perbankan Syariah

Vol. 7. No.2, Agustus 2018: 64-02, ISSN (cet): 2355-1755 | ISSN (online): 2579-

6437

1 67

perusahaan. Faktor ini mencakup lingkungan industri dan lingkungan bisnis makro, ekonomi, politik, hukum, teknologi, kependudukan dan sosial budaya. Menurut Porter, lingkungan eksternal dibagi kedalam dua kategori yaitu lingkungan makro dan lingkungan industri.

Elemen-elemen yanng ada dalam lingkungan ini memberikan pengaruh yang tidak langsung pada perusahaan. Elemen-elemen yang perlu diperhatikan addalah sebagai berikut :

1) Organisasi Industri

2) Pengaruh Ekonomi

3) Pengaruh Sosial, Budaya, Demografi dan Lingkungan

4) Politik, Pemerintah dan hukum

5) Teknologi

6) Kompetitor Bisnis

\section{b. Analisis Lingkungan Internal}

Lingkungan internal adalah menekankan pada identifikasi dan evaluasi kekuatan dan kelemahan pada era fungsional bisnis, termasuk manajemen pemasaran, keuangan, produksi, penelitian dan pengembangan sistem informasi manajemen dan hubungan antara semuanya. Strategi didesain sebagai bagian dari usaha memperbaiki kelemahan perusahaan dan mengubahnya menjadi kekuatan bahkan menjadi kompetisi yang baik merupakan kekuatan perusahaan yang tidak dengan mudah ditiru atau disamakan dengan pesaing (David, 2010).

Elemen-elemen yang perlu diperhatikan addalah sebagai berikut :

1) Manajemen

2) Marketing

3) Keuangan / Akuntansi

4) Produksi / Proses

5) Penelitian \& Pengembangan

\subsection{Tahap Perumusan Strategi}

Tahap untuk merumuskan strategi yang dapat digunakan untuk menjawab visi dan misi perusahaan dapat digunakan beberapa macam alternatif pilihanstrategi. Strategi tersebut didasarkan pada analisis faktor internal dan faktor eksternal pada lingkungan perusahaan sehingga dapat memberikan hasil dan mengevaluasi strategi yang terbaik untuk perusahaan.

Menurut David (2008) beberapa alat analisis yang digunakan dalam menentukan strategi antara lain yaitu:

\section{Internal Factor Evaluation Matrikx (Matriks IFE)}

Analisis lingkungan internal atau evaluasi faktor internal mencakup pada kekuatan dan kelemahan yang dimiliki perusahaan yang kemudian dapat dianalisis melalui identifikasi faktor-faktor internal apa saja yang terkait dengan perusahaan. Data dan informasi aspek internal dapat diperoleh dari 
beberapa aspek yang ada pada perusahaan, misalnya dari aspek manajemen, keuangan,produksi dan pemasaran.

\section{Eksternal Factor Evaluation Matriks (Matriks EFE)}

Analisis lingkungan eksternal atau evaluasi faktor eksternal, digunakan untuk mengevaluasi faktor-faktor eksternal perusahaan yang mencakup faktor peluang dan ancaman dari perusahaan. Data eksternal dikumpulkan melalui hal hal yang berhubungan dengan ekonomi, sosial, budaya, lingkungan demografi, teknologi, kebijakan pemerintah, hukum dan kompetitif perusahaan. Dari masing masing faktor internal dan eksternal, kemudian diberikan bobot nilai berdasarkan pengaruh faktor-faktor tersebut. Bobot IFE pada sumbu horizontal dan bobot EFE pada sumbu vertikal.

\section{Internal Eksternal Matrikx (Matriks IE)}

Analisis Internal dan Eksternal (Matriks IE) merupakan tahap masukan dari formulasi strategi yang mencakup pemetaan dari analisis faktor internal dan eksternal yang telah didapat, yaitu total skor bobot IFE pada sumbu horizontal dan total skor bobot EFE pada sumbu vertikal. Pada matriks IE digunakan untuk mempertajam analisis yang telah dilakukan pada matriks IFE dan EFE yan selanjutnya dipetakan pada matriks IE untuk memperoleh strategi bisnis di tingkat perusahaan yang lebih jelas.

\section{Analisis Matriks SWOT}

Analisa SWOT adalah sebuah bentuk analisis situasi dan kondisi yang bersifat deskriptif (memberi gambaran). Analisa ini menempatkan situasi dan kondisi sebagai sebagai faktor masukan, yang kemudian dikelompokkan menurut kontribusinya masing-masing. Analisis ini sangat dikenal sebagai alat pencocokan yang penting yang membantu para manajer mengembangkan empat jenis strategi (David, 2008). SWOT digunakan untuk menilai kekuatan-kekuatan dan kelemahan-kelemahan dari sumber-sumber daya yang dimiliki perusahaan dan kesempatan-kesempatan eksternal dan tantangan-tantangan yang dihadapi (Jogiyanto, 2005, p. 46).

\section{Analisis Quantitative Strategic Planning Matrix (QSPM)}

Langkah selanjutnya setelah diperoleh alternatif strategi melalui tahapan pencocokan dengan menggunakan matriks IFE, EFE, IE dan SWOT, kemudian dipilih strategi terbaik dengan menggunakan alat analisis QSPM. QSPM menentukan daya tarik relatif dari berbagai strategi berdasarkan seberapa jauh faktor keberasilan kunci internal dan eksternal diperbaiki (David 2008). Strategi memberikan dasar untuk menghasilkan dan mengevaluasi alternatif strategi yang layak. Alternatif strategi yang telah dirumuskan dalam Eksternal Factor Evaluation (EFE) dan Internal Factor Evaluation (IFE) dipilih menggunakan matriks Internal Eksternal (IE) dan Analisis Strenght-Weakness-Opportunity-Threat (SWOT), kemudian diurutkan dengan Quantitative Strategic Planning Matriks (QSPM) menurut angka prioritas yang paling besar. 
Jurnal Ekonomi dan Perbankan Syariah

Vol. 7. No.2, Agustus 2018: 64-02, ISSN (cet): 2355-1755 | ISSN (online): 25796437

169

\subsection{Landasan Hukum}

1. Al-quran

Dasar dalam membangun konsep gadai terdapat dalam QS. Al-Baqarah

(2) ayat 283 :

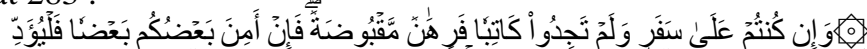

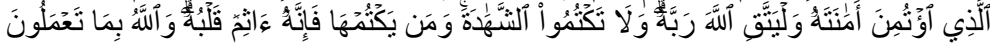

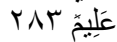

Artinya: “Jika kamu dalam perjalanan (dan bermu'amalah tidak secara tunai) sedang kamu tidak memperoleh seorang penulis, Maka hendaklah ada barang tanggungan yang dipegang[180] (oleh yang berpiutang). akan tetapi jika sebagian kamu mempercayai sebagian yang lain, Maka hendaklah yang dipercayai itu menunaikan amanatnya (hutangnya) dan hendaklah ia bertakwa kepada Allah Tuhannya; dan janganlah kamu (para saksi) Menyembunyikan persaksian. dan Barangsiapa yang menyembunyikannya, Maka Sesungguhnya ia adalah orang yang berdosa hatinya; dan Allah Maha mengetahui apa yang kamu kerjakan.

2. Hadits

Hadist 'Aisyah r.a. yang diriwayatkan oleh Imam Muslim :

Artinya: "Rasulullah SAW membeli makanan dari seorang Yahudi dengan menggadaikan baju besinya" (HR. Muslim).

Hadits dari Anas bin Malik r.a. yang diriwiyatkan oleh Ibnu Majah :

Artinya: "Rasulullah SAW menggadaikan baju besinya kepada seorang Yahudi di Madinah dan menukarnya dengan gandum untuk keluarganya" (HR. Ibnu Majah).

Hadits dari Abu Hurairah r.a. yang diriwayatkan oleh Imam Al-Bukhari :

Artinya: "Kendaraan dapat digunakan dan hewan ternak dapat pula diambil manfaatnya apabila digadaikan. Penggadai wajib memberikan nafkah dan penerima gadai boleh mendapatkan manfaatnya" (HR. Al-Bukhari).

Hadits riwayat Abu Hurairah r.a. :

Artinya: "Barang gadai tidak boleh disembunyikan dari pemilik yang menggadaikan, baginya risiko dan hasilnya” (HR. Asy-Syafi'i dan AdDaruquthni).

3. Fatwa Dewan Syariah Nasional

a) Fatwa Dewan Syariah Nasional Majelis Ulama Indonesia No.

25/DSN-MUI/III/2002, tentang Rahn

b) Fatwa Dewan Syariah Nasional Majelis Ulama Indonesia No. 26/DSN-MUI/III/2002, tentang Rahn Emas 
70 | Masitoh Syahidah, Azis Budi Setiawan, Endang Ahmad Yani: Strategi Pemasaran Produk Ar-Rum BPKB Pada Pegadaian Syariah CPS Margonda

\subsection{ARRUM BPKB}

ARRUM adalah pembiayaan syariah untuk pengembangan Usaha Mikro Kecil dan Menengah (UMKM) dengan menggunakan BPKB/BPHTB Kendaraan bermotor sebagai jaminan. Pembiayaan yang diberikan maksimal $70 \%$ dari taksiran harga barang jaminan (kendaraan bermotor). Pinjaman bisa diajukan mulai dari $1-150$ juta, tergantung nilai dari kendaraan bermotor yang dijaminkan.

Pembiayaan ARRUM (Ar Rahn Untuk Usaha Mikro) pada Pegadaian Syariah memudahkan para pengusaha kecil untuk mendapatkan modal usaha dengan jaminan kendaraan. Kendaraan tetap pada pemiliknya sehingga dapat digunakan untuk mendukung usaha sehari-hari.

\section{METODOLOGI PENELITIAN}

\subsection{JENIS PENELITIAN}

Penelitian kuantitatif menurut Sugiyono yaitu Metode penelitian yang berlandaskan pada filsafat positivisme, digunakan untuk meneliti pada populasi atau sampel tertentu, pengumpulan data menggunakan instrumen penelitian, analisis data bersifat kuantitatif/statistik, dengan tujuan untuk menguji hipotesis yang telah ditetapkan (Sugiyono, 2015, p. 8).

\subsection{JENIS DATA :}

\subsubsection{Primer}

Data primer merupakan data yang di dapat dari sumber pertama baik dari individu maupun perseorangan seperti hasil dari wawancara yang bisa di lakukan oleh peneliti, (Umar, 2013).

Data primer yang digunakan untuk penelitian kali ini adalah data hasil wawancara, Data jumlah nasabah dan omzet dan data lainnya yang dieroleh langsung dari Kantor Pegadaian Syariah CPS Margonda, Depok.

\subsubsection{Sekunder}

Data sekunder adalah merupakan data primer yang telah di olah lebih lanjut dan disajikan baik oleh pihak pengumpul data primer atau pihak lain, misalnya dalam bentuk table-tabel atau bentuk diagram (Umar, 2013)

Data sekunder yang digunakan dalam penelitian in iadalah data-data eksternal perusahaan seperti data jumlah UMKM kota depok, jumlah tingkat pengangguran, regulasi-regulasi, dll.

\subsection{TEKNIK PENGAMBILAN DATA}

1. Wawancara

Wawancara adalah salah satu teknik pengumpulan data yang pelaksanaannya dapat dilakukan secara langsung berhadapan dengan yang diwawancarai dan dapat juga secara tidak langsung, yaitu dengan memberti daftar pertanyaan untuk dijawab pada kesempatan lain (Umar, 2013, p. 51) 
Jurnal Ekonomi dan Perbankan Syariah

Vol. 7. No.2, Agustus 2018: 64-82, ISSN (cet): 2355-1755 | ISSN (online): 2579-

6437

| 71

Wawancara ini dilakukan beberapa kali baik secara formal maupun non formal. Yang menjadi narasumber wawancara adalah Pimpinan Cabang, Penaksir dan Pengelola Marhun.

\section{Observasi langsung}

Observasi Merupakan cara pengumpulan data melalui proses pencatatan subjek (orang), objek (benda), atau kejadian tanpa adanya pertanyaan atau komunikasi dengan individu yang diteliti (Sanusi, 2016, p. 111).

Kegiatan observasi langsung di kantor Pegadaian Syariah CPS Margonda bertujuanuntuk melihat bagaimana kegiatan operasional seharihari.

3. Dokumentasi

Cara pengumpulan data dengan dokumentasi biasanya dilakukan untuk mengumpulkan data sekunder dari berbagai sumber, baik secara pribadi maupun kelembagaan (Sanusi, 2016, p. 114)

Dokumentasi yang diperoleh untuk penelitian ini adalah data pencapaian produk ARRUM BPKB dan berapa produk lainnya, gambaran aktifitas kegiatan operasional, dll.

\subsection{POPULASI DAN SAMPEL}

\subsubsection{Populasi}

Populasi adalah seluruh kumpulan elemen yang menunjukkan ciri-ciri tertentu yang dapat digunakan untuk membuat kesimpulan. (Sanusi, 2016)

Populasi dari penelitian kali ini adalah karyawan yang terlibat langsung dengan produk pembiayaan ARRUM BPKB di Pegadaian SyariahCPS Margonda.Ada 3 orang yang terlibat langsung dengan produk ARRUM, yaitu pimpinan cabang, bagian penaksir dan pengelola marhun.

\subsubsection{Sampel}

Sampel adalah bagian dari jumlah dan karakterisitik yang dimiliki oleh populasi tersebut (Sugiyono, 2015). Sampel yang dibutuhkan berasal dari karyawan dan nasabah Cabang Pegadaian Syariah (CPS) Margonda, Depok.

\subsection{TEKNIK PENGAMBILAN SAMPEL}

Pada penelitian kali ini, teknik sampling yang digunakan adalah sampling jenuh. Dimana, sampling jenuh adalah penentuan sampel bila semua anggota populasi digunakan sebagai sampel (Sugiyono, 2015). Oleh karena itu, sampel yang diambil adalah seluruh populasi yang berjumlah tiga orang yang terdiri pimpinan cabang, bagian penaksir dan pengelola marhun. 
72 | Masitoh Syahidah, Azis Budi Setiawan, Endang Ahmad Yani: Strategi Pemasaran Produk Ar-Rum BPKB Pada Pegadaian Syariah CPS Margonda

\subsection{INSTRUMEN PENELITIAN}

Menurut Sugiyono (2015) Instrumen penelitian adalah suatu alat yang digunakan untuk mengukur fenomena alam maupun sosial yang diamati (Sugiyono, 2015).

Tabel 2. Instrumen Penelitian

\begin{tabular}{|c|c|c|}
\hline \multirow{2}{*}{$\begin{array}{l}\text { Evaluasi } \\
\text { SWOT }\end{array}$} & Faktor Internal & $\begin{array}{l}\text { Indikator : } \\
\text { 1) Manajemen } \\
\text { 2) Marketing } \\
\text { 3) Keuangan / Akuntansi } \\
\text { 4) Produksi / Proses } \\
\text { 5) Penelitian \& Pengembangan } \\
\text { 6) Sistem Informasi Manajemen (SIM) }\end{array}$ \\
\hline & Faktor Eksternal & $\begin{array}{l}\text { Indikator : } \\
\text { 1) Organisasi Industri } \\
\text { 2) Pengaruh Ekonomi } \\
\text { 3) Pengaruh Sosial, Budaya, Demografi dan } \\
\text { Lingkungan } \\
\text { 4) Politik, Pemerintah dan hukum } \\
\text { 5) Teknologi } \\
\text { 6) Kompetitor Bisnis }\end{array}$ \\
\hline
\end{tabular}

Sumber :Data diolah (David, 2012)

\subsection{ANALISIS DATA}

Tahapan pengolahan data melalui 3 tahapan analisis. Menurut Rangkuti, proses penyusunan strategis melalui tiga tahap analisis. Kemudian pada tahap akhir analisis adalah tahap pengambilan keputusan yang diperoleh dari penilaian pada tahap analisis yang dibuat secara kualitatif maupun kuantitatif, sehingga dapat diperoleh keputusan yang sesuai dengan kondisi perusahaan. 3 tahapan pengolahan dan analsiis data tersebu yaitu (Rangkuti, 2017, p. 23) :

1. Tahap pengumpulan data

2. Tahap analisis

3. Tahap pengambilan keputusan

Untuk lebih jelasnya, berikut adalah bagan alur tahapan pengolahan dan analisis SWOT menurut Rangkuti (2017) :

Bagan 3.1Kerangka Formulasi Strategis

\begin{tabular}{|lc|}
\hline \multicolumn{2}{|c|}{ 1. TAHAP PENGUMPULAN DATA } \\
\hline \\
Evaluasi Faktor Eksternal & Evaluasi Faktor Internal \\
\hline & 2. TAHAP ANALISIS \\
\hline
\end{tabular}


Jurnal Ekonomi dan Perbankan Syariah

Vol. 7. No.2, Agustus 2018: 64-82, ISSN (cet): 2355-1755 | ISSN (online): 2579-

6437

| 73

Matriks Tows

Kuadran

Analisis

SWOT

\section{TAHAP PENGAMBILAN KEPUTUSAN}

Matriks Perencanaan Strategi Kuantitatif

Sumber : Rangkuti, 2017

\section{PEMBAHASAN}

\subsection{Profil Pegadaian Syariah CPS Margonda}

Nama Perusahaan : Pegadaian Syariah CabanMargonda

Alamat : Jl. Margonda Raya, No. 239, KemiriMuka, Beji, KotaDepok, Jawa Barat, 16424

Telepon : :021) 77212293

Jenis Lembaga : Lembaga Keuangan Syariah Non Bank

Tahun Berdiri : Sejak tahun 2005

Status : Kantor Cabang

Jumlah Karyawan:

- Cabang : 7 tetap, 5 outsourch

- Unit : 20 orang (2 karyawan per unit)

\subsection{Sejarah Pegadaian Syariah CPS Margonda}

Pegadaian Syariah Cabang Margonda atau biasa disebut Cabang Pegadaian Syariah (CPS) Margonda adalah Lembaga Keuangan Syariah (LKS) Non Bank yang berdi pada Tahun 2005. Pegadaian syariah CPS Margonda ini adalah satu-satunya CPS yang ada di Kota Depok yang membawahi 10 UPS (Unit Pembantu Syariah) Pegadaian Syariah yang ada di Kota Depok

\subsection{IDENTIFIKASI FAKTOR-FAKTOR KEKUATAN, KELEMAHAN, PELUANG DAN ANCAMAN)}

Berdasarkan Identifikasi analisis lingkungan eksternal dan internal Produk ARRUM BPKB di Pegadaian Syariah CPS Margonda, maka diperoleh 
74 | Masitoh Syahidah, Azis Budi Setiawan, Endang Ahmad Yani: Strategi Pemasaran Produk Ar-Rum BPKB Pada Pegadaian Syariah CPS Margonda

faktor strategis internal dan eksternak perusahaan yang berupa kekuatan, kelemahan peluang dan ancaman perusahaan. Faktor-faktor tersebut adalah sebagai berikut :

Tabel 4.1 Faktor-faktor Internal dan Eksternal

\begin{tabular}{|c|c|}
\hline No & Faktor-Faktor Strategi Eksternal \\
\hline & Peluang \\
\hline 1 & Merupakan perusahaan BUMN \\
\hline 2 & Adanya Program WUB (Wirausaha Baru) Jawa Barat \\
\hline 3 & Peduduk muslim di Kota Depok terus meningkat \\
\hline 4 & Pengusaha UMKM di Kota Depok semakin meningkat \\
\hline \multirow[t]{2}{*}{5} & $\begin{array}{l}\text { Produk mendukung program pemerintah Kota Depok dalam pengembangan UMKM } \\
\text { kota Depok }\end{array}$ \\
\hline & Ancaman \\
\hline 1 & Semakin banyaknya pesaing baru \\
\hline 2 & $\begin{array}{l}\text { Adanya Peraturan OJK No. 31/POJK.05/2016 tentang Usaha Pergadaian yang } \\
\text { melegalkan usaha Gadai Swasta }\end{array}$ \\
\hline 3 & Proses pencairan yang lebih lama dibandingkan pesaing \\
\hline 4 & Persyaratan yang lebih banyak dibandingkan pesaing (Gadai swasta) \\
\hline
\end{tabular}

\begin{tabular}{|l|l|}
\hline No & \multicolumn{1}{|c|}{ Faktor-Faktor Strategi Internal } \\
\hline & \multicolumn{1}{c|}{ Kekuatan } \\
\hline 1 & Memiliki agen-agen pemasaran \\
\hline 2 & Melakukan cross selling, up selling dan call selling secara rutin \\
\hline 3 & Terjun langsung ke pasar dengan melakukan canvassing \\
\hline 4 & Memiliki Aplikasi Sahabat Pegadaian dan Pegadaian Digital \\
\hline 5 & Transaksi sesuai syariah (tidak menggunakan bunga) \\
\hline 6. & $\begin{array}{l}\text { Ujroh/Mu'nah yang ditawarkan lebih murah dibandingkan pesaing (gadai } \\
\text { swasta) }\end{array}$ \\
\hline 1 & \multicolumn{1}{c|}{ Kelemahan } \\
\hline 2 & Kurangnya SDM di CPS Margonda \\
\hline 3 & Riset dan pengembangan hanya dilakukan di Pegadaian pusat, tidak di cabang. \\
\hline 4 & Proses pencairan yang masih lebih lama dibandingkan dengan pesaing \\
\hline
\end{tabular}


Jurnal Ekonomi dan Perbankan Syariah

Vol. 7. No.2, Agustus 2018: 64-82, ISSN (cet): 2355-1755 | ISSN (online): 2579-

6437

| 75

4.4. Matriks EFAS

Tabel 4. 1 Matriks EFAS

(Eksternal Strategic Factors Analysis Summary)

\begin{tabular}{|c|c|c|c|}
\hline Faktor-Faktor Strategi Eksternal & & & \\
\hline Peluang & Bobot & Rating & Skor \\
\hline Merupakan perusahaan BUMN & 0.18 & 3.67 & 0.67 \\
\hline $\begin{array}{l}\text { Adanya Program WUB (Wirausaha Baru) } \\
\text { Jawa Barat }\end{array}$ & 0.08 & 3.00 & 0.25 \\
\hline $\begin{array}{l}\text { Peduduk muslim di Kota Depok terus } \\
\text { meningkat }\end{array}$ & 0.12 & 3.33 & 0.39 \\
\hline $\begin{array}{llll}\begin{array}{l}\text { Pengusaha UMKM di } \\
\text { semakin meningkat }\end{array} & \text { Kota } & \text { Depok } \\
\end{array}$ & 0.12 & 3.67 & 0.43 \\
\hline $\begin{array}{l}\text { Produk mendukung program pemerintah } \\
\text { Kota Depok dalam pengembangan } \\
\text { UMKM kota Depok }\end{array}$ & 0.15 & 3.67 & 0.55 \\
\hline TOTAL & & & \\
\hline Ancaman & & & \\
\hline Semakin banyaknya pesaing baru & 0.11 & 1.00 & 0.11 \\
\hline $\begin{array}{l}\text { Adanya Peraturan } \\
\text { 31/POJK.05/2016 tentang } \text { OJ No. } \\
\text { Pergadaian yang melegalkan usaha Gadai } \\
\text { Swasta }\end{array}$ & 0.07 & 1.33 & 0.09 \\
\hline $\begin{array}{l}\text { Proses pencairan yang lebih lama } \\
\text { dibandingkan pesaing }\end{array}$ & 0.10 & 1.67 & 0.16 \\
\hline $\begin{array}{l}\text { Syarat yang diberikan pesaing lebih } \\
\text { mudah }\end{array}$ & 0.08 & 1.67 & 0.13 \\
\hline TOTAL & 1 & & 2.78 \\
\hline
\end{tabular}

Sumber : Data diolah 
76 | Masitoh Syahidah, Azis Budi Setiawan, Endang Ahmad Yani: Strategi Pemasaran Produk Ar-Rum BPKB Pada Pegadaian Syariah CPS Margonda

\subsection{MATRIKS IFAS}

Tabel 4.2 Matriks IFAS

(Internal Strategic Factors Analysis Summary)

\begin{tabular}{|c|c|c|c|}
\hline Faktor-Faktor Strategi Internal & & & \\
\hline Kekuatan & Bobot & Rating & Skor \\
\hline Memiliki agen-agen pemasaran & 0.08 & 3.00 & 0.23 \\
\hline $\begin{array}{l}\text { Melakukan cross selling, up selling dan } \\
\text { call selling secara rutin }\end{array}$ & 0.13 & 4.00 & 0.53 \\
\hline $\begin{array}{l}\text { Terjun langsung ke pasar dengan } \\
\text { melakukan canvassing }\end{array}$ & 0.10 & 3.00 & 0.30 \\
\hline $\begin{array}{l}\text { Memiliki Aplikasi Sahabat Pegadaian dan } \\
\text { Pegadaian Digital }\end{array}$ & 0.09 & 2.67 & 0.24 \\
\hline $\begin{array}{l}\text { Transaksi sesuai } \\
\text { menggunakan bunga) }\end{array}$ & 0.10 & 3.33 & 0.33 \\
\hline $\begin{array}{l}\text { Ujroh/Mu'nah yang ditawarkan murah } \\
\text { dibandingkan pesaing }\end{array}$ & 0.10 & 3.67 & 0.37 \\
\hline \multicolumn{4}{|l|}{ Kelemahan } \\
\hline Kurangnya SDM di CPS Margonda & 0.12 & 2.00 & 0.23 \\
\hline $\begin{array}{l}\text { Belum ada divisi khusus pemasaran untuk } \\
\text { melakukan pemasaran poduk }\end{array}$ & 0.12 & 1.67 & 0.19 \\
\hline $\begin{array}{l}\text { Riset dan pengembangan hanya dilakukan } \\
\text { di Pegadaian pusat, tidak di cabang. }\end{array}$ & 0.09 & 2.00 & 0.19 \\
\hline $\begin{array}{l}\text { Proses pencairan yang lebih lama } \\
\text { dibandingkan dengan pesaing }\end{array}$ & 0.07 & 1.33 & 0.10 \\
\hline TOTAL & 1 & & 2.72 \\
\hline
\end{tabular}

Sumber : Data diolah

\subsection{KUADRAN ANALISIS SWOT}

Kuadran Analisis SWOT menggunakan hasil dari analiss matriks IFAS dan EFAS Pegadaian Syariah CPS Margonda. Hasil analisis matriks 
Jurnal Ekonomi dan Perbankan Syariah

Vol. 7. No.2, Agustus 2018: 64-82, ISSN (cet): 2355-1755 | ISSN (online): 2579-

6437

177

IFAS diperoleh dari total skor kekuatan sebesar 0.60 dan kelemahan sebesar 0.40. Sementara matriks EFAS diproleh total skor peluang sebesar0.65dan ancaman sebesar 0.35

Sumbu X diperoleh dari hasil pengurangan total skor kekuatan dikurangi dengan total skor kelemahan yaitu 0.20. Dan sumbu Y diperoleh dari hasil pengurangan total peluang dikurangi dengan ancaman yaitu0,30. Berikut kuadran analisis SWOT pada Pegadaian Syariah CPS Margonda.

\section{Bagan 4.1 Kuadran SWOT}

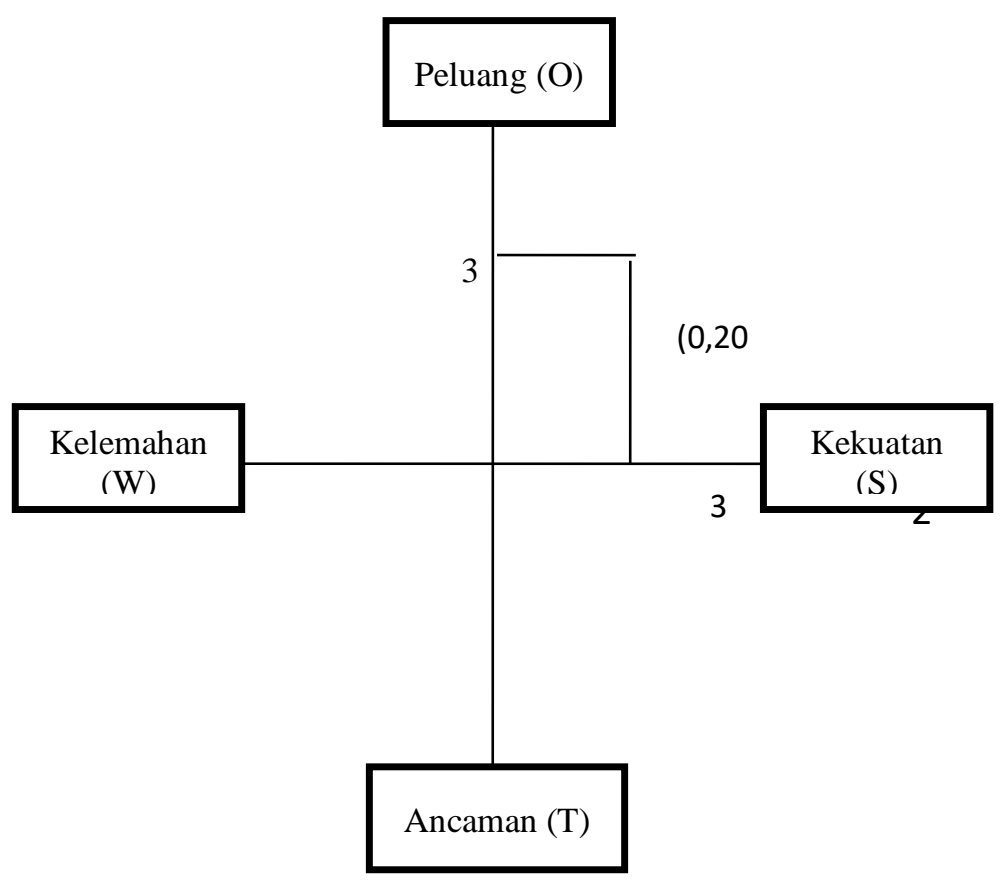

\section{Sumber : Data diolah}

Dari kuadran analisis SWOT diatas dapat ditarik kesimpulan bahwa perusahaan berada pada Kuadran I (positif, positif), ini menandakan sebuah organisasi yang kuat dan berpeluang. Rekomendasi yang strategi yang diberikan adalah progressive, artinya organisasi dalam kondisi prima dan mantap sehingga sangat dimungkinkan untuk terus melakukan ekspansi, memperbesar pertumbuhan dan meraih kemajuan secara maksimal.

Oleh karena itu, alternative strategi yang dapat diterapkan oleh perusahaan adalah strategi S-O (Strength-Opportunities) yaitu dengan memanfaatkan peluang yang dimiliki perusahaan terhadap kekuatan perusahaan. 
78 | Masitoh Syahidah, Azis Budi Setiawan, Endang Ahmad Yani: Strategi Pemasaran

Produk Ar-Rum BPKB Pada Pegadaian Syariah CPS Margonda

\subsection{ANALISIS MATRIKS SWOT}

Tabel 4.3 Matriks SWOT

\begin{tabular}{|c|c|c|}
\hline SW & \begin{tabular}{|l} 
KEKUATAN \\
( STRENGTH ) \\
1. Memiliki agen-agen pemasaran \\
2. Melakukan cross selling, up \\
selling dan call selling secara rutin \\
3. Terjun langsung ke pasar dengan \\
melakukan canvassing \\
4. Memiliki Aplikasi Sahabat \\
Pegadaian dan Pegadaian Digital \\
Transaksi sesuai syariah (tidak \\
menggunakan bunga) \\
6. Ujroh/Mu'nah yang ditawarkan \\
lebih murah dibandingkan pesaing \\
(gadai swasta)
\end{tabular} & 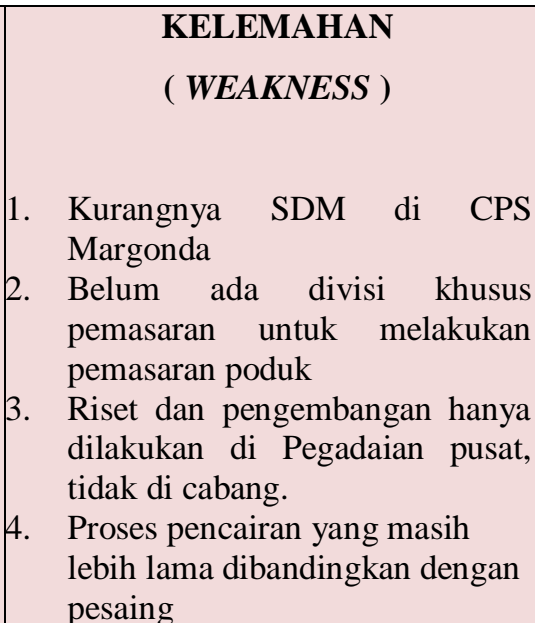 \\
\hline $\begin{array}{l}\text { 1. Merupakan } \\
\text { perusahaan } \\
\text { BUMN } \\
\text { 2. Adanya Program } \\
\text { WUB (Wirausaha } \\
\text { Baru) Jawa Barat } \\
\text { 3. Peduduk muslim di } \\
\text { Kota Depok terus } \\
\text { meningkat } \\
\text { 4. Pengusaha } \\
\text { UMKM di Kota } \\
\text { Depok semakin } \\
\text { meningkat } \\
\text { 5. Produk } \\
\text { mendukung } \\
\text { program } \\
\text { pemerintah Kota } \\
\text { Depok dalam } \\
\text { pengembangan } \\
\text { UMKM kota } \\
\text { Depok }\end{array}$ & $\begin{array}{l}\text { STRATEGI SO } \\
\text { 1. Sosialisasi biaya ujroh yang } \\
\text { murah kepada pengusaha } \\
\text { UMKM secara lebih masif (S2, } \\
\text { O1) } \\
\text { 2. Memperbanyak dan memperluas } \\
\text { iklan terkait produk ARRUM } \\
\text { BPKB oleh agen-agen pemasaran } \\
\text { (S1, O4) } \\
\text { Bekerjasama dengan } \\
\text { kementerian Koperasi dan } \\
\text { UMKM, dinas koperasi Kota } \\
\text { Depok untuk memberikan } \\
\text { literasi dan mempromosikan } \\
\text { produk ARRUM BPKB (S5, S6, } \\
\text { W1, W5) } \\
\text { Bekerjasama dengan komunitas- } \\
\text { komunitas Ekonomi syariah } \\
\text { seperti MES (Masyarakat } \\
\text { Ekonomi Syariah) dalam } \\
\text { memberikan literasi produk } \\
\text { ARRUM (S5, S6, W3, W4) } \\
\text { Bekerjasama dengan program } \\
\text { WUB Jawa Barat dalam } \\
\text { memberikan literasi dan }\end{array}$ & 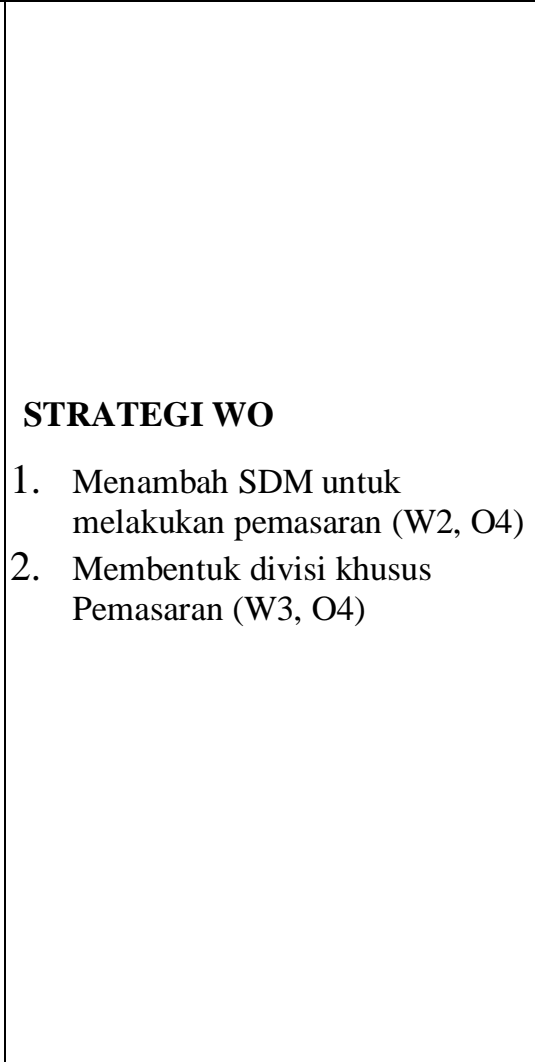 \\
\hline
\end{tabular}


Jurnal Ekonomi dan Perbankan Syariah

Vol. 7. No.2, Agustus 2018: 64-82, ISSN (cet): 2355-1755 | ISSN (online): 2579-

6437

79

\begin{tabular}{|c|c|c|}
\hline & $\begin{array}{llr} & \text { mempromosikan } & \text { produk } \\
& \text { ARRUM BPKB (S1, S3, W2) } \\
\text { 6. } & \text { Bekerjasama } & \text { dengan kampus } \\
\text { ekonomi } & \text { syariah dan } \\
\text { mahasiswanya untuk melakukan } & \text { lasian } \\
\text { literasi produk ARRUM (S1, S3, } & \text { W3,W4) }\end{array}$ & \\
\hline $\begin{array}{l}\text { ANCAMAN } \\
\text { ( THREATS ) } \\
\\
\text { 1. } \begin{array}{l}\text { Semakin } \\
\text { banyaknya pesaing } \\
\text { baru }\end{array} \\
\text { 2. } \\
\text { Adanya } \\
\text { Peraturan } \\
\text { OJK No. } \\
\text { 31/POJK.05/2016 } \\
\text { tentang Usaha } \\
\text { Pergadaian yang } \\
\text { melegalkan usaha } \\
\text { Gadai Swasta } \\
\text { 3. Proses pencairan } \\
\text { yang lebih lama } \\
\text { dibandingkan } \\
\text { pesaing } \\
\text { 4. Persyaratan yang } \\
\text { lebih banyak } \\
\text { dibandingkan } \\
\text { pesaing (Gadai } \\
\text { swasta) }\end{array}$ & $\begin{array}{l}\text { STRATEGIST } \\
\text { 1. Mempertahankan ujroh yang } \\
\text { murah untuk menarik minat } \\
\text { UMKM (S6, T1) } \\
\text { 2. Mengadakan seminar ekonomi } \\
\text { syariah untuk mensosialisasikan } \\
\text { pentingnya transaksi sesuai } \\
\text { syariah (S3, T1) }\end{array}$ & $\begin{array}{l}\text { STRATEGI WT } \\
\text { 1. } \\
\text { Menyederhanakan proses } \\
\text { pencairan pembiayaan } \\
\text { ARRUM. (W4,T4) } \\
\text { 2. } \\
\text { Melakukan riset ke masyarakat } \\
\text { terkait produk ARRUM dan } \\
\text { produk pesaing (W2, T1, T2) }\end{array}$ \\
\hline
\end{tabular}

Sumber : Data diolah

\subsubsection{QSPM}

Hasil strategi yang diperoleh pada matriks SWOT terdapat 12 alternatif strategi yang dapat diterapkan pada produk ARRUM BPKB oleh Pegadaian Syariah CPS Margonda. Dari 12 strategi tersebut, yang menjadi prioritas untuk dapat diterapkan oleh oleh Pegadaian Syariah CPS Margonda adalah strategi S-O. Dalam tahapan pembuatan matriks QSPM ini diperoleh data faktor-faktor kekuatan, kelemahan, peluang dan ancaman dari matriks IFAS dan matriks EFAS. Adapun strategi S-O yang diperoleh adalah sebagai berikut : 
80 | Masitoh Syahidah, Azis Budi Setiawan, Endang Ahmad Yani: Strategi Pemasaran Produk Ar-Rum BPKB Pada Pegadaian Syariah CPS Margonda

1. Sosialisasi biaya ujroh yang murah kepada pengusaha UMKM secara lebih masif (S2, O1)

2. Memperbanyak dan memperluas iklan terkait produk ARRUM BPKB oleh agen-agen pemasaran (S1, O4)

3. Bekerjasama dengan kementerian Koperasi dan UMKM, dinas koperasi Kota Depok untuk memberikan literasi dan mempromosikan produk ARRUM BPKB (S5, S6, W1, W5)

4. Bekerjasama dengan komunitas-komunitas Ekonomi syariah seperti MES (Masyarakat Ekonomi Syariah) dalam memberikan literasi produk ARRUM (S5, S6, W3, W4)

5. Bekerjasama dengan program WUB Jawa Barat dalam memberikan literasi dan mempromosikan produk ARRUM BPKB (S1, S3, W2)

6. Bekerjasama dengan kampus ekonomi syariah dan mahasiswanya untuk melakukan literasi produk ARRUM (S1, S3, W3,W4)

Keenam strategi tersebut pada akhirnya akan dipilih 1 strategi yang menjadi prioritas dalam pengambilan keputusan. Alternatif strategi S-O kemudian diperingkatkan sesuai dengan nilai Attractiveness Scores kemudian dihitung atau ditotalkan menjadi Total Attractiveness Score yang selanjutnya diurutkan sesuai nilai tertinggi dari strategi terpilih seperti pada tabel dibawah ini. Dari hasil analisis QSPM prioritas strategi terpilih adalah strategi kedua yaitu Meningkatkan Sosialisasi biaya ujroh yang murah terhadap UMKM secara lebih masif dengan nilai 6,123.Hasil perhitungan strategi QSPM adalah sebagai berikut :

1. Sosialisasi biaya ujroh yang murah kepada pengusaha UMKM secara lebih masif $(5,768)$

2. Memperbanyak dan memperluas iklan terkait produk ARRUM BPKB oleh agen-agen pemasaran $(5,830)$

3. Bekerjasama dengan kementerian Koperasi dan UMKM, dinas koperasi Kota Depok untuk memberikan literasi dan mempromosikan produk ARRUM BPKB $(5,623)$

4. Bekerjasama dengan komunitas-komunitas Ekonomi syariah seperti MES (Masyarakat Ekonomi Syariah) dalam memberikan literasi produk ARRUM (4,523)

5. Bekerjasama dengan program WUB Jawa Barat dalam memberikan literasi dan mempromosikan produk ARRUM BPKB $(4,733)$

6. Bekerjasama dengan kampus ekonomi syariah dan mahasiswanya untuk melakukan literasi produk ARRUM $(4,133)$

Prioritas strategi yang dipilih adalah Memperbanyak dan memperluas iklan terkait produk ARRUM BPKB oleh agen-agen pemasaran serta semakin banyak pelaku UMKM yang ada di Indonesiamenjadi faktor utama dipilihnya strategi ini. Dengan strategui in, diharapkan semakin meningkatnya nasabah produk ARRUM BPKB tersebut. 
Jurnal Ekonomi dan Perbankan Syariah

Vol. 7. No.2, Agustus 2018: 64-82, ISSN (cet): 2355-1755 | ISSN (online): 2579-

6437

| 81

\section{KESIMPULAN}

Berdasarkan hasil dan pembahsan yang telah dilakukan terkait Strategi Pemasaran Produk ARRUM BPKB pada Pegadaian Syariah CPS Margonda, dapat ditarik kesimpulan sebagai berikut:Dari hasil perhitungan kuadran analisis SWOT dapat disimpulkan bahwa produk ARRUM BPKB berada di Kuadran I yaitu dalam kondisi Progressive. Yaitu strategi S-O lah yang tepat untuk diterapkan. Dan Strategi S-O yang dihasilkan adalah : Sosialisasi biaya ujroh yang murah kepada pengusaha UMKM secara lebih masif; Memperbanyak dan memperluas iklan terkait produk ARRUM BPKB oleh agen-agen pemasaran; Bekerjasama dengan kementerian Koperasi dan UMKM, dinas koperasi Kota Depok untuk memberikan literasi dan mempromosikan produk ARRUM BPKB; Bekerjasama dengan komunitaskomunitas Ekonomi syariah seperti MES (Masyarakat Ekonomi Syariah) dalam memberikan literasi produk ARRUM; Bekerjasama dengan program WUB Jawa Barat dalam memberikan literasi dan mempromosikan produk ARRUM BPKB; Bekerjasama dengan kampus ekonomi syariah dan mahasiswanya untuk melakukan literasi produk ARRUM.

Dan berdasarkan perhitungan QSPM, prioritas strategi dengan Total Nilai Daya Tarik (TAS) tertinggi adalah Memperbanyak dan memperluas iklan terkait produk ARRUM BPKB oleh agen-agen pemasaran. 
82 | Masitoh Syahidah, Azis Budi Setiawan, Endang Ahmad Yani: Strategi Pemasaran Produk Ar-Rum BPKB Pada Pegadaian Syariah CPS Margonda

\section{DAFTAR PUSTAKA}

Ali, Z. (2008). Hukum Gadai Emas Syariah. Jakarta: Sinar Grafika.

Amin, M. (2005). Mengatasi Masalah Dengan Pegadaian Syariah. Jakarta: Renaisan.

Arifin, Z. (2002). Dasar-dasar Manajemen Bank Syariah. Jakarta: Alvabet.

David, F. R. (2005). Manajemen Strategis: Konsep. Jakarta: Salemba Empat. Jogiyanto. (2005). Sistem Informasi Strategik untuk Keunggulan Kompetitif. Yogyakarta: Andi Offset.

Kotler, P., \& Amstrong. (2003). Dasar-dasar Pemasaran. Jakarta: PT. Indeks. Pegadaian Syariah. (t.thn.). Arrum-BPKB : Pegadaiansyariah.co.id. Dipetik $01 \quad 08, \quad 2018, \quad$ dari $\quad$ www.Pegadaiansyariah.co.id: http://pegadaiansyariah.co.id/arrum-bpkb-2415

Rangkuti, F. (2017). ANALISIS SWOT : Teknik Membedah Kasus Bisnis. Jakarta: PT. Gramedia Pustaka Utama.

Sanusi, A. (2016). Metode Penelitian Bisnis. Jakarta: Salemba Empat.

Sugiyono, P. D. (2015). Metode Penelitian Kuantitatif, Kualitatif dan R\&D. Bandung: Alfabeta.

Umar, H. (2013). Metode Penelitian untuk Skripsi dan Tesis Bisnis. Jakarta: Rajawali Pers. 